\title{
DOCUMENTACIÓN PEDAGÓGICA: MÁS ALLÁ DEL ESTÁNDAR. IMÁGENES DE INFANCIA EN DEVENIR
}

Pedagogical documentation: beyond the standard. children's images to become Documentação pedagógica: além do padrão. imagens de crianças a tornar-se

\section{Isabel María Fernández García (1)}

\section{Encarnación Soto Gómez (2)}

(1) Universidad de Málaga, España. Teléfono: 696665955. Correo electrónico: isabelmfg@hotmail.com

(2) Universidad de Málaga, España. Teléfono: 952132624. Correo electrónico: esoto@uma.es

\section{Resumen}

En la presente comunicación, centrada en el marco del Prácticum II de la Facultad de Ciencias de la Educación de la Universidad de Málaga, se expone el diseño de una propuesta de Prácticum reflexiva, ofrecida y sostenida por nuestra tutora de prácticas, entorno a la documentación pedagógica en la escuela como mirada empática y compleja hacia los procesos de aprendizaje de la infancia. Se reflexiona acerca de la relevancia que la documentación pedagógica posee, como herramienta innovadora de evaluación formativa, para posibilitar cambios reflexivos en nuestra imagen de infancia, así como en nuestros modos cotidianos de acercarnos a ella, posibilitando la reconstrucción del pensamiento práctico docente y la manera de entender y estar en la profesión.

Palabras clave: Documentación pedagógica; reconstrucción docente; imagen de infancia.

\begin{abstract}
In the present communication, centered in the framework of the Practicum II of the Faculty of Education Sciences of the University of Malaga, the design of a reflexive Practicum proposal, offered and sustained by our internship tutor, is exposed pedagogical documentation in the school as an empathic and complex look towards childhood learning processes. It reflects on the relevance that pedagogical documentation has, as an innovative tool for formative evaluation, to enable reflective changes in our childhood image, as well as in our daily ways of approaching it, enabling the reconstruction of practical teaching thinking and the way to understand and be in the profession.

Keywords: Pedagogical documentation; teacher reconstruction; childhood image

Documentación pedagógica: más allá del estándar. Imágenes de infancia en devenir




\section{Resumo}

Na presente comunicação, centrada no âmbito da Prática II da Faculdade de Ciências de Educação da Universidade de Málaga, apresenta-se o desenho de uma proposta de Prática reflexiva, oferecida e sustentada pela nossa tutora de estágio, em relação à documentação pedagógica na escola, com um olhar empático e complexo para com os processos de aprendizagem na infância. Reflete-se sobre a relevância que a documentação pedagógica possui como ferramenta inovadora de avaliação formativa. Desse modo possibilita mudanças reflexivas na nossa imagem de infância, bem como nos nossos modos cotidianos de aproximarmo-nos dela, possibilitando a reconstrução do pensamento prático docente e a maneira de entender e estar na profissão.

Palavras-chave: Documentação pedagógica; reconstrução de professores; imagem da infância

\section{Introducción}

En la presente comunicación se sintetiza la experiencia de mi encuentro con la documentación pedagógica como herramienta de evaluación formativa orientada al aprendizaje con la infancia, en colaboración con mi tutora de prácticas. En palabras de Hoyuelos (2007), documentar supone la "recogida y exposición sistemática y estética (a través de escritos, imágenes, paneles, vídeos, palabras de los niños y niñas, productos gráficos) de los procesos educativos. Es un arte para entender la cultura infantil: su forma de pensar, hacer, preguntar, teorizar o desear" (p.5).

\section{Contextualización}

La experiencia se sitúa en el Prácticum II del Grado de Educación Infantil (30 días), tercer curso del grado, en la Universidad de Málaga (8 créditos), cuando la tutora propone al grupo (seis alumnos), adentrarnos en la cotidianeidad de las escuelas desde la documentación pedagógica, poniendo en juego una mirada más allá de los estándares objetivos de evaluación hegemónicos (Santos Guerra, 2017).

\section{Diseño, desarrollo y evaluación}

Atendiendo a la complejidad del proceso de documentar pedagógicamente en la escuela, la tutora nos sostuvo desde una propuesta metodológica que movilizaba varios ejes. Se trataba de documentar no como acción aislada, sino como un entramado de aprendizaje donde, con la documentación: 1. Estructuraríamos nuestro diario de prácticas a través de Documentación pedagógica: más allá del estándar. Imágenes de infancia en devenir 
escenas de infancia recogidas. 2. Profundizaríamos en nuestras miradas e interpretaciones documentales en una página compartida, como foro de conversación reflexiva de los procesos de aprendizaje documentados. 3. Al final del proceso, elaboraríamos paneles de documentación que expondríamos públicamente en la facultad, centrando nuestra atención en profundizar las historias de aprendizaje de la infancia sin la intervención directiva de un adulto.

¿Hacia dónde nos lleva, entonces, la documentación pedagógica?, ¿qué implica de nuestro ser docente? Específicamente, la esencia de documentar en la escuela, como estrategia evaluativa, se fundamenta en que "hay un adulto que se interesa por lo que hacen los niños, y hace el esfuerzo de recoger los elementos necesarios para descifrar la complejidad de lo que ve" (Altimir, 2011, p.40-41).

Como docentes en formación en las escuelas de prácticas, documentar nos llevaba hacia lo que Rinaldi (2001) denomina una escucha visible, dado que el objetivo era el de explicitar reflexivamente la actividad cotidiana de las niñas y los niños a fin de pensar con sus historias de aprendizaje en un sentido evaluativo-formativo: ¿qué recorridos de pensamiento generan los niños y niñas en espacios educativos diseñados para ellos; y cómo observar e interpretar sus acciones nos lleva como maestros a reajustar y mejorar nuestra propia práctica para con la infancia?

Es de este modo como la acción de documentar se iba convirtiendo en sostén de nuestro rol docente en prácticas, tomando la observación y la reflexión como elementos clave de nuestras competencias docentes esenciales y como muestra de respeto hacia las historias de aprendizaje de la infancia.

Documentar, verbo activo, nos introducía en procesos de evaluación formativa basados en un constante aprender a aprender (Pérez Gómez, 2012) desde las documentaciones generadas, reflexionadas con la tutora, que a través de su continuo feedback nos permitía reorientar nuestra propia actividad profesional, permaneciendo cerca de las zonas de aprendizaje de la infancia.

Desde este permanecer cerca de, nuestra mirada iba descubriendo una infancia hasta entonces impensada, percibida ahora documentalmente como comunidad de inconmesurables con formas complejas de darse al mundo. Una experiencia que transformó mi conocimiento práctico (Pérez Gómez, 2012) en relación a qué significa evaluar en la escuela, y a mi imagen de infancia.

Al hilo de ello, Malaguzzi (1989, en Hoyuelos, 2013) sostiene que hay cientos de imágenes de infancia que implican maneras concretas de relacionarnos con ella. Esto, Documentación pedagógica: más allá del estándar. Imágenes de infancia en devenir 
supone un punto de inflexión sobre esa imagen de "infancia universal", abriéndonos a una infancia en singular.

Aparecen ante mi mirada escenas de infancia inéditas con nombres y rostros concretos: Xeray (4), que andaba por el patio acariciando a una guitarra creando su propia pulsión lúdica, se encuentra con Esperanza (4), quien se la pide. Como adulta, si no hubiese estado en disposición de documentar, probablemente me habría acercado a ambos pensando que surgiría un desencuentro por la posesión del objeto. No obstante, documentar me permitió acercarme de otro modo, desde una distancia cercana a la trama de sus relaciones, las cuales tambalean mis estereotipos evaluativos en cuanto a una "imagen de infancia egocéntrica". Xeray no sólo le tendió la guitarra sino que inició una especie de tutorización entre coetáneos, compartiéndole sus trucos manuales para relacionarse con el objeto. Más allá: se retiró no para marcharse, sino para contemplar a Esperanza tocando la guitarra, desde una mirada quieta y honda que parecía estar redescubriéndola.

Gracias a las retroalimentaciones de mi tutora, sostén provocador, pude atreverme a ir más allá de imágenes de infancia institucionales; orientándome desde la pregunta y la emoción, allí donde se encuentran los niños y niñas, hacia miradas múltiples. Ello, me permitía la autorregulación sobre mi propio aprendizaje, no sólo como reconstrucción de determinados contenidos, sino como experiencia de evaluación transformativa de mi propia acción docente. Como adulta, salir de mí, mirar a la infancia como infancia y preguntarme: ¿Cómo viven el niño, la niña, su relación con el mundo, y qué exige ello de mi rol profesional?

\section{Conclusiones}

Vivir la documentación pedagógica, mediación constructivista y situada, permite un triple proceso acción-reflexión-mejora: giro epistemológico en la propia práctica y en la manera de entender la evaluación, tomando la escucha interpretativa como eje estructurador del hacer y el pensar. Documentar provoca detenernos y narrar sistemáticamente el presente continuo que la infancia compone desde sus acciones.

\section{Referencias}

Altimir, D. (2011). ¿Cómo escuchar a la infancia? Barcelona: Octaedro.

Documentación pedagógica: más allá del estándar. Imágenes de infancia en devenir 
Hoyuelos, A. (2007). Documentación como narración y argumentación. Revista aula de infantil, 34, 1-4. Recuperado de: http://www.grao.com/revistas/aula-infantil/039ladocumentacion/documentacion-como-narracion-y-argumentacion

Hoyuelos, A. (2013). La estética en el pensamiento y obra de Loris Malaguzzi. Barcelona: Octaedro.

Pérez Gómez, Á.I. (2012). Educarse en la era digital. Madrid: Morata.

Rinaldi, C. (2001). La pedagogía de la escucha. Innovations in Early Education, (8), p. $1-4$. http://www.bama.org.ar/sitio2014/sites/default/files/_archivos/merkaz/Jomer_on _line/rh_pedagogia_escucha.pdf

Santos Guerra, M.A. (2017). Organización, liderazgo y evaluación en las instituciones educativas. Bogotá: Uniminuto. 